\title{
Hospital Closures and Community Care \\ Correspondence between the National Schizophrenia Fellowship and the Minister for Health
}

Last year the Bulletin (June 1984, 8, 112-114) published a statement on hospital closures and community care from the National Schizophrenia Fellowship which was widely circulated to influential bodies. This statement was sent to the Minister for Health, Mr Kenneth Clarke, and on 29 May 1984, he replied to the NSF. The NSF wrote back to $\mathrm{Mr}$ Clarke on 2 July, to which he again responded in a letter of 2 October.

These three letters are published below and it is hoped that they will be of interest to our readership.

29 MAY 1984

Dear Mrs Major*

Thank you for your letter of 23 February about mental hospital closures and community care. I understand that you also wrote to Norman Fowler and Lord Glenarthur on this subject and I hope you will accept this as a reply to all three of your letters.

Your letter and the accompanying statement raise some fundamental issues concerning the care of people suffering from mental illness. I am sorry you have not received an early reply but I hope you will take the delay as an indication of the importance which I and my colleagues attach to this subject, and the time which we have spent going into the issues you raise with our officials here. I am reassured to find that the real differences are not so great as they might appear. I hope that this letter will reassure you that we share your concern that the new pattern of services should be better not worse than the old, and dispose of one or two misconceptions. I can also assure you and your fellow members that we are not in fact going to let services for mentally ill people deteriorate.

\section{The aim we share}

I welcome what you say in appreciation of the new psychiatric policies and the closing of old, run-down hospitals. As you imply, if we can provide services which really give the patient the care and treatment he needs at the time he needs it, in his own community, it must help to lessenthe social isolation and the stigma of the past.

\section{The need for more care}

On some of the points on which you express concern, I broadly agree. For example, I agree that we are still well short of a comprehensive network of fully adequate aftercare services, although progress has been made. Similarly, I agree that we do not yet have sufficient suitable residential places. It is difficult to get precise figures, because so many of the more enterprising forms of accommodation (such as are discussed in the recent report, 'Housing

*Mrs Joyce Major. Chairman of the NSF for Mentally III and Mentally Handicapped People', which covers about 3,000 places for people with mental illness) do not show up in our figures about those who have been sponsored for residential accommodation. The accommodation that is available is not always mobilized to the best advantage. There is a greater deficit in relation to day centre places; though here again the figures do not show all the daytime facilities used by people with mental illness. I accept too, that the help offered to relatives has often been inadequate. As you say, they are often the people who provide the 'care in the community', and they have had too little help from the statutory authorities-which have sometimes aimed all their services at those without families. We are now trying to put this right. For instance, at the beginning of this year our DHSS Social Work Service, through its Development Group, launched a major project on the needs of informal carers, which has attracted a good deal of interest already. The opening national conference will be followed by seven regional ones.

I and my colleages regard it as an urgent task to make further progress. I am not sure if you know that we issued a circular to health and local authorities in January (HC(84)2): in this the main paragraph on 'service priorities' says: 'In particular, Ministers wish to see authorities place an early emphasis on ... the development generally of community-based services especially those for people with mental handicap or mental illness.'

This repeats what was said in Care in Action in 1981; and through our system of Regional Reviews we are now getting some measure of the response since 1981. The Circular also requires each regional health authority to prepare by March 1985 a comprehensive ten-year Regional strategic plan. We will be keen to ensure that these map out positive and feasible strategies for developing community-based services. Our annual review discussions and the outline strategies that we have already received show that most health authorities are taking these tasks seriously.

What we are doing

On other points, I fear that you misunderstand what we are doing. You speak of 'the drive, at all costs, to move mental patients out of hospital and into the community'. The answer to that is straightforward: there is no such drive. Similarly you say "current plans will close large mental hospitals before adequate alternative provision exists for patients'. On the contrary, everything we have said on this subject has repeated and reinforced the specific statement made in the 1975 White Paper, Better Services for the Mentally Ill:

We welcome this opportunity to stress that our aim is not the 
closure or run down of mental illness hospitals as such; but rather to replace them with a local and better range of facilities. It will not normally be possible for a mental hospital to be closed until the full range of facilities described in chapter 4 has been provided throughout its catchment area and has shown itself capable of providing for newly arising patients a comprehensive service independent of the mental hospital. Moreover, even then, it will not be possible to close the hospital until it is no longer required for the long-stay patients admitted to its care before the local services came into operation. [Para 11.5]

You refer to closure proposals for a number of mental illness hospitals in and around London. As far as three of these are concerned-Horton, Long Grove and West Park-there are at present no firm plans for closure. You may perhaps have seen references to a review being carried out by the South West Thames RHA of the future pattern of mental illness and mental handicap services for the areas currently served by the Epsom cluster of hospitals. These include Horton, Long Grove and West Park together with two mental handicap hospitals, St Ebba's and The Manor. The five hospitals have more than 3,300 patients, employ about 3,800 staff and occupy about 420 acres. Because all five hospitals have declining numbers of patients and because there is scope for yielding considerable revenue to finance better community services through the sale of part of the Epsom estate, the different health authorities are to look at all the needs together, so as to agree on plans which on the one hand organize the remaining service to the best advantage of in-patients, and on the other allow the sale of the land likely to bring most revenue to help finance new developments nearer the patients' homes.

I think I should say a little more to explain our policies and put them in context, so that I can convince you that there is no 'drive at all costs to move mental patients out of hospital'. You probably know that the numbers in mental illness hospitals began falling in the '50s; the biggest single reason is that since that time fewer patients have been embarking on long-stay care, but in the ' 60 s and ' 70 s another significant factor was the discharge of existing long-stay patients, most of whom were no longer mentally ill, but some of whom, as you imply, did have continuing mental illness which was not always adequately cared for in the community. The rate of discharge of long-stay patients has declined since then: for example, the number of people discharged annually after a stay of over 5 years was around 2,400 in the early ' 70 s, but had fallen to 1,253 in 1982.

Meanwhile the development of community facilities, as foreshadowed long ago in the 1959 Mental Health Act, has continued, although it has not been as quick as we would like. Governments, health authorities and local authorities have all found it difficult to find the funds to build up a new service at the same time as funding the old service which has continued to cost more and more in real terms, despite the fall in the number of in-patients, partly because of rising standards of care. It is of course difficult to release really substantial funds until a hospital is closed.

Two new elements have come into the picture within the last few years, and I will describe them both, because I think they have been combined to create the misleading picture set out in your letter and statement. I will start with the 'Care in the Community' initiative which you mention. This was not particularly concerned with mentally ill patients; it covered all kinds of long-term care. The starting point was, to quote the 1981 consultative document: 'Most of the people who need long-term care can and should be looked after in the community. This is what most of them want for themselves and what those responsible for their care believe to be best.'

The aim was to remove the obstacles to community care which had trapped some people in hospital even though all concerned thought this was inappropriate. The circular issued in 1983 brought to fruition the ideas discussed in the consultative document, and has enabled many health and local authorities to make constructive plans for alternative care. But, as we foreshadowed in 1981, plans for mentally ill people though valuable, are much less numerous than those for, for example, mentally handicapped people, simply because after the earlier discharges there are not so many long-stay patients who have no need for hospital care and would benefit by a transfer to community care. So we have taken an initiative on discharges, but there is no question of us discharging patients 'at all costs'.

The second initiative, concerned with closures, is less well documented. Indeed, all we have really done is to take steps to see that existing policy is implemented. That policy is, put shortly, that every district should have its own psychiatric service, including adequate beds for in-patient care; that where a district has a mental illness hospital in its area and the hospital is well placed to serve as a base for care, it should continue to do so; but that when there are mental illness hospitals which are not well placed to perform this function for any district the health authorites concerned should make effective plans to provide alternative services for the districts concerned and then, in the words of our 1981 paper, Care in Action:

Make arrangements satisfactory to patients and staff locally for the closure, over the next 10 years or so, of those mental illness hospitals which are not well placed to provide a service reaching out into the community and are already near the end of their useful life. Such closures should provide a source of staff, capital, and revenue to support the development of the new pattern of health services, including community psychiatric nursing, for the mentally ill and perhaps help to support the development of services provided by the local authorities.

Here again we are not rushing to push the patients out of hospital. In many cases, some of the patients may be moved to another hospital, either closer to the area from which they are admitted and with which they may still have family and other ties or to another large hospital at which a higher quality of care can be provided. (For example, in the case of Banstead Hospital, significant progress has already been made in providing in-patient facilities in the districts served by Banstead Hospital, both for new patients and for existing patients at Banstead. At the 
same time it is planned to move other patients to Horton Hospital once accommodation has been upgraded to provide a better environment than can be achieved at Banstead.)

This is not the place for a detailed statistical analysis, but a few approximate figures may help to give the picture. There are probably rather less than 70,000 mentally ill inpatients today, and the annual reduction is slower than it was. Indeed the main reason for the fall now is deaths among the eldest of the 'old long-stay' patients, of whom the 1975 White Paper said they 'have become so accustomed to hospital life-in some cases so institutionalized-that it would be inhuman to discharge them from the hospital that has, in effect, become their home'-a policy we still adhere to. Another factor will be the result of our 'Care in the Community' initiative to speed up provision of community care in cases where discharge to such care would be in the patient's interest. The 1981 consultative document estimated there might be 'up to $5,000^{\prime}$ such patients-perhaps 20 or 25 in each health district. But taking all the factors together, I would hardly expect that the number of in-patients in, say, 1994 would fall much below 60,000 . I do not offer that as a firm forecast; our statisticians would need to do more work to weigh up the current trends; but $I$ hope this very simple presentation will help you and your members to re-assess your comment on 'the move to speed up the discharge process'-remembering that around 1970 the number of in-patients was falling by over 4,000 in a single year.

Part of my own contribution has been to say to Regional Health Authorities-and I suspect that many of your members will agree with me- that where a plan for an area has, after due consultation been decided on, it should be pushed forward energetically and effectively. I believe much damage has been done in the past, not least to the mental illness hospitals themselves, through health authorities allowing things to drift, so that staff and patients are left in uncertainty, and the service suffers many of the disadvantages of a closure, without the confident step forward towards better services which could result from the change to new facilities once it arrives.

To sum up, our policy is that a patient should be discharged only if a discharge is in his best interests. Closures are a consequence, not a cause, of discharges; and they will be possible only when the new community services now being planned are there to take over the patients from the old services, either as in-patients or in the community, according to their individual needs.

\section{My comments on your statement}

You put seven points to us:

I(i): I can be helpful on this particular aspect, I think. Any proposals for the closure of a psychiatric hospital which are opposed by the local Community Health Council are referred to Ministers before a decision is taken. We are also able to call in other closure proposals which raise other broader issues of importance. We consider all proposals on their merits, of course, but are particularly interested in the direct and indirect effects on patients' services that the proposed closure may have. The availability of adequate alternative provisions is clearly a very important factor to be taken into account in our deliberations.

I(ii): I certainly do not suggest that the life of a long-stay mental hospital patient is necessarily worse than life for the homeless vagrant. We have always taken the line that, although it is primarily for the responsible consultant to determine when a particular patient is ready to leave hospital, good practice requires that before any patient is discharged the consultant should satisfy himself that there are adequate support facilities outside the hospital. I accept that things do not always turn out as well as the doctors hope; and I must remind you also that comparatively few in-patients meet the criteria for compulsory detention, so that most of them must be allowed to discharge themselves when they choose, whether the rest of us think this wise or not.

I(iii): I have already quoted our recent circular which urges health authorities to invest resources to develop these services. I share your view that in-service training is important, and my staff here are seeking to encourage it, and specifically to increase the share of post-certificate training for nurses which goes to psychiatric nurses.

I(iv): I agree with the general sense of your recommendation, and in particular I am very conscious that the provision of regional secure units will not meet all needs. They are in fact specifically intended only to meet the needs of patients who are, among other things, expected to respond to treatment within 18 months or so. We have been taking up the wider issues with health authorities over the last year or so, culminating in a discussion which I had with RHA chairmen last December. It is interesting to note that the number of locked wards, etc, outside the RSUs, reported by health authorities has been increasing over the last few years-the latest return is about 900 beds-at the same time the number of mentally ill prisoners reported by prison medical officers has fallen, and we hope to lower the number still further.

II(i): I am very glad to support psychiatrists and social workers trying to implement carefully planned discharge policies. We have been very encouraged to see the careful and detailed planning, providing a range of choices to meet different needs, which are included in most of the schemes we have seen under the 'Care in the Community' initiative. My officers have seen some which were less complete, and there they have sought to have the gaps filled. I very much hope that many of your local branches will be able to join in this sort of planning with their local health authorities and local authorities. We are currently looking at problems about after-care, and if we may we will borrow your sentence: 'We want discharge to a known address, and to a caring person, and a continuing liaison with the medical and social services.'-with due acknowledgement- to cite in this connection! It says just what we feel is needed. Though again we must put in a proviso about patients who will not wait for the known address or the caring person, 
and who cannot be tied thereafter to contacts they chose not to maintain.

II(ii): We too regard the community psychiatric nursing services as a key element, and welcome the fact that the numbers are growing so fast all over the country. There are currently something like 2,000 community psychiatric nurses.

II(iii): I have partly covered this under II(i) above, but I can add that I agree with all three of your specific points.

\section{Conclusion}

I have written at considerable length, because I think it is very important that your members, who are so deeply involved, should be satisfied that I and my colleagues are aware of the dangers as well as of the potential rewards of our policies. We do not mean to allow these dangers to materialize. On the contrary, we mean to see that facilities for 'care in the community' mount faster, rather than slower, than the discharge of people who are going to continue to need such care so that we make good the arrears which we know exist. My immediate task is to persuade the Regional Health Authorities to mobilize their financial resources-prime the pump, if you like-so that the work of building community resources begins straight away, in the places where it is most needed. If they have a fund they can use it to build up services in district $A$ which is served by an unsuitable hospital; the distant hospital serving A can then be closed; and the saving used to build up community services in B. Clearly this needs regional planning. That is why I hope that when the regional plans are published next year we shall be able to satisfy you that good progress has been made and further substantial advances are planned. (Meanwhile I think you will be interested in the attached announcement about the pilot 'Care in the Community' projects.)

I should like to add two things. Firstly, we fully appreciate the special problems faced by people suffering from schizophrenia and by their relations. We are having a special look at these in our consideration of after-care problems. Secondly, I should like to say how much we appreciate the contribution made by yourselves and the Richmond Fellowship to the continuing debate on the development of our community mental health services. I hope that debate can move forward on an informed basis, and that the Government's policies in this important area of social care can become more widely known and better understood.

Yours sincerely

Kenneth Clarke

\section{Dear Mr Clarke}

2 JULY

I have already written briefly to thank you for your long, considered letter of 29 May, commenting on our joint statement with the Richmond Fellowship. After discussing your letter with colleagues, I am now writing, as promised, to take up some of the issues you raised.
You say that on some points we misunderstand what you are doing, one of them being our belief in the 'drive, at all costs, to move mental patients out of hospital into the community'. You say there is no such drive. The wording may not accurately describe conscious, formulated policy. It does accurately describe what-owing perhaps to a combination of causes at different levels-is happening, often with agonizing results for patients and caring relatives.

You say that health authorities are to complete their plans by next year, and that you are telling RHAs that 'where a plan for an area has, after due consultation been decided on, it should be pushed forward energetically and effectively'. The main thrust of all your Department's papers and pronouncements, for many years, under all shades of government, has been towards getting patients 'into the community'. These are elements in the 'drive'. It is reinforced at health authority levels by the widely popular 'anti-psychiatry' campaigners and the 'rights' (let everyone do his own thing) gospellers. At the present time of financial stringency it is also strongly reinforced by the weakness of psychiatric consultants in competition with other specialties, which, in the words of one health administrator, 'carry more clout'.

We believe that plans are being worked out on an insufficient information base. We are perhaps to blame for failing to realize sooner that health authorities are well advanced in massive planning which will be difficult to modify. We have lately been seeing a large number of planning and consultative documents and-with limited resources-have done our best to point out what we see as defects. We are of course particularly concerned with the severely chronically ill, who include so many of our patients, and especially the new long stay. We find very great confusion and differences of opinion about probable numbers, and vagueness of ideas about what to do with them.

On these two points we had hoped for some dialogue with your Department. In 1979 we published a discussion paper, 'How Many Places?', asking for stringent criticism. We were promised comments, but have had none. Last summer the DHSS said they had information on hospitalhostels. We asked for it in November, but have received nothing.

We are convinced that the better statistical forecasting promised by Lord Glenarthur last year, and pilot schemes tested and proved, are essential before plans are 'pushed forward'.

The 'drive' began with the 1962 hospital plan, which was based on misinformation. We believe it is continuing, with insufficient information still. The lack mainly concerns the severely chronically ill. Our overriding preoccupation with these, together with the imminent crystallizing of plans, may perhaps excuse our use of the phrase 'at all costs'. In our perspective, these severely chronically ill will continue to be the chief sufferers from the new plans.

You say: 'Closures are a consequence, not a cause, of discharges.' (Is it perhaps a rather petty debating point to 
observe that a recent DHSS paper argued that an 800-bed hospital could be closed without any discharges.) We have no experience of closures. We have a great deal of experience of the effects of run-down, and our profound anxieties stem from this experience. Even more baneful than unwelcome discharges has been the growth of refusal to admit. Those of us who have been 'living with schizophrenia' for a quarter of a century or so look nostalgically at the ease of entry to hospital in earlier years, when the main difficulty was to persuade the patient to go; compared with the present situation when the patient has acquired some insight, and the caring relatives some knowledge of warning signs of crisis, but all efforts to secure a 'bed' are frustrated.

A symptom of what is happening is NW Thames RHA's finding that, in the five years to 1981 , their waiting lists increased 35 per cent.

The same perspective-which amounts to seeing the most severely and permanently ill as most in need-led us to speak of the move to speed up the discharge process. Gross annual discharges have of course fallen as the base has contracted, and as those more amenable to discharge have gone. There cannot be many left 'unnecessarily incarcerated'; we are close to the hard core, and it is in relation to this that we descry acceleration and the likelihood of insecurely founded decisions.

Incidentally your Department published, four days before the date of your letter, Lord Glenarthur's written answer to a question by Lord Mottistone in which he said: 'Provisional figures indicate that on 31 December 1982, the latest date for which figures are available, the total number of available beds in mental illness hospitals and units in England was 83,510.' It is difficult in these matters to be sure that one is comparing like with like. But, after allowing for a proportion of empty beds, there is still a surprising gap between this and your estimate of rather less than 70,000 mentally ill in-patients at present. If the figures are comparable they would seem to imply a fall at an annual rate of over 6,000 (acceleration indeed).

We have described the effects of the run-down in various of our publications, and I will not burden this letter with repetition; but I am enclosing a copy of our recent written evidence for the House of Commons Social Services Committee, in case you should have time to glance at it. I should be grateful if you could, anyway, look at the two short quotations at the top of page 1 , and at the 'tailpiece' (after Appendix D). These come from Wiltshire Social Services Department, a DHSS/Home Office paper and a DHSS document, so are to be presumed free from any bias that might affect us.

We note with approval, if we may say so, the general stress throughout your letter on the need for health authorities to see that adequate arrangements are made for the more severely chronically ill. In our comments on the consultative document, Care in the Community, we suggested there might be good arguments for making the health service primarily responsible for the whole range of care for the mentally ill (as, we understand, is the case in
Northern Ireland and New Zealand). We note also that some health authorities now use 'in the community' to describe their own smaller, more local institutions. This is a welcome shift in the connotations of that protean phrase, which earlier seemed always to imply a weight of reliance on local authority services. This apparent reliance and constant talk of joint working has helped to fuel our fears that adequate arrangements will not be made within the time scale of projected closures. The very real obstacles to joint working are well known. We see no hope of their being rapidly overcome, except in relatively few areas where conditions are favourable-first and foremost the existence of a few determined individuals on both sides of the divide.

What is Government policy for filling the gaps, when closures are approved, and these determined health and local authority members and officers do not come forward? We greatly fear that in fact it would not be possible to secure funds from the health authorities on an adequate scale, or in time, for joint arrangements with local authorities, for care in the community to be organized within the time scale of the projected closures.

We welcome your assurance that you are not going to let services deteriorate. They are of course already miserably deficient; and in some respects have been deteriorating. The only notable improvement is the appearance in some areas of community psychiatric nurses-with very great deficiencies in numbers in many other areas. The total planned figure of $2,000 \mathrm{CPNs}$ in 1984 is, in our opinion, inadequate.

Better Services for the Mentally III contained some bright gleams of light; but they have dimmed. For instance, in your quotation from it on page 2 of your letter, the last sentence said it would not be possible to close a hospital until no longer required for its long-stay patients: and your further quotation, page 4, said it would be inhuman to discharge them from the hospital that has, in effect, become their home. But towards the top of page 4, you now say that 'in many cases' some patients may be moved to another hospital.

Perhaps, amongst other minor points on which we seem to differ, we might challenge your statement, top of page 3 , that the biggest single reason for the fall in hospital populations is that since the '50s fewer patients each year have been embarking on long-stay care. Since 1974 the number of such patients has scarcely varied. We would also question what you say in the same paragraph that in the ' $60 \mathrm{~s}$ and '70s most of the discharged long-stay patients were no longer mentally ill. This does not accord with our experience, or with the fact that very many are not thought able to live independently by their relatives 10 or 20 years later.

We find it surprising that you draw our attention to informal patients' ability to discharge themselves, while you write elsewhere of people 'trapped in hospital'. Far from being trapped, these informal patients have no wish to leave, having no alternative home to go to, nor care in the community; staying in hospital therefore offers them asylum in its best sense. 
We cannot but be sad that you have agreed to the request of the West Midlands RHA to close St Wulstan's Hospital, which has a more than regional intake. This is a unique hospital, of international reputation, skilled in the techniques of rehabilitation, and every effort should now be made to see that these skills are not lost, and at least are taught elsewhere. Eighty per cent of the patients do not have a home to go to, and we remain sceptical that sufficient modern facilities are available elsewhere. Accommodation alone is not enough. It will be scandalous if the annual $£ 350,000$ saved on St Wulstan's is spent on anything other than further developing patient services for the mentally ill.

We are very grateful to you for agreeing to meet us, and discuss our members' problems so freely with you on 23 May. This, and your letter, are greatly appreciated, and we thank you again.

Yours sincerely

JOYCE MAJOR

2 OCTOBER

\section{DeAr Mrs Major}

Thank you for your letter of 2 July in response to mine of $29 \mathrm{May}$, in which you raise a number of points about plans and policies.

We attach great importance to detailed and co-ordinated health service planning, for all services, not just the mental illness specialty. Our circular $\mathrm{HC}(82) 6$, issued in March 1982 to introduce the revised planning system, explained its three-fold purpose thus: (1) to provide a framework within which health authorities can review and develop their services in the light of national policies and priorities; (2) to assist Ministers in assessing progress towards national goals and in reviewing those goals; and (3) to help achieve the best use of resources.

A feature of the revised planning system is that plans are kept under review to enable them to be modified as circumstances change. Strategic plans, covering a forward period of ten years (or longer where major capital developments are concerned) are produced only after a comprehensive review of all services, involving professional people as well as planners, and having regard to prevailing national policies and priorities as well as to local priorities. As you know, mental illness services are a national priority.

The planning system involves wide consultation. Bodies with a close interest should be consulted informally throughout the development of plans and programmes. Formal consultation should take place at district level on both strategic plans and the forward programme (the second year of annual programmes). It is in this way that organizations like the NSF, as well as the stautory Community Health Councils, can play an invaluable role, and I hope they will play a full part in the local discussion process.

I recognize and appreciate your long-standing concern with the chronically mentally ill, and I hope that all the discussions that are going on now as part of the planning process will remove some of the vagueness of ideas which you have encountered.

Could I say here that I was concerned to read that you had approached my Department for information on hospital-hostels and received no reply. I am not sure what form your request took but we can find no trace of a written approach. We shall gladly let you have whatever information we have available. May I suggest that you write to Mr G. A. Golding, the Secretary to our Mental Illness Research Liaison Group (Room C418 at the above address), explaining what it is you require.

I think I can at once clear up some of the confusion about figures. In commenting on what I said in my previous letter about in-patients you quote information in Parliament about 'available beds'. There is indeed a striking gap between the number of beds and the number of in-patients. To clear this point up I can do no better than enclose a copy of Statistical Notes prepared by the Department's statisticians. Note 13/84 uses information from the Mental Health Enquiry to provide a number of tables which will be of general interest to the Fellowship. You will see from chart 3 of table 7 that at 31 December 1982, the number of in-patients was 70,881 ; in the last few weeks we have been given a provisional figure for 31 December 1983 of 69,000 . But for your immediate purpose the most relevant tables are tables 2 and 3 in Note $2 / 84$ on "hospital activity'. From these you will see that the number of inpatients has remained more than 10,000 below the number of available beds throughout the last 10 years.

This clears up your point about the 1982 statistics. But I think it has also a wider importance in building an accurate picture of the present position. The figures illustrate my comment that closures are a consequence of discharges, rather than the other way round. In the last 30 years a number of factors have led psychiatrists all over the world to discharge their patients more quickly, irrespective of the beds available to them. There were indeed far more empty beds available in England in 1982 than there were in, say, the fifties. In terms of statistics, health authorities could close twelve 800-bedded hospitals tomorrow, and leave inpatients numbers still at their present level. In terms of human beings it is not so simple; but when they have closed half a dozen or so they will be better able to find the resources to provide the community care which the patients already discharged so badly need, in particular the severely chronically ill about whom you write.

I accept your point that difficulties in arranging needed admissions can be a major weakness in services where there is too little community care. You may have noticed from the announcement last month that we have undertaken a small-scale initiative to improve co-ordination of after-care for schizophrenia, and this is one of the aspects which is being tackled, though it will take some time before we can hope for any results. You will be interested to know that my officials have been getting hold of copies of your recently-published, Code of Practice for Discharges, in this connection.

I was interested in your comments about the part to be 
played by health authorities. I must stress that we have always seen the term 'community care' as just as applicable to activities of health authorities as to those of local authorities, and in the case of services for mental illness, I have no doubt the main burden of care will always rest with the health authorities, as indeed the 1975 White Paper indicated.

We do regard a degree of joint working with local authorities as essential. The Social Service Department is in a key position in relation to a whole range of services, so joint planning is important. However, the actual pattern of services can vary, and in some places the health services have been able to turn for help to voluntary bodies, housing associations, etc, so that the actual direct contribution needed from the social services department has been comparatively small. And health authorities can now transfer funds to local authorities-including local housing authorities-and voluntary organizations for as long as necessary to provide community care for people moving out of long-stay hospitals. Joint finance funds can be used on extended terms where necessary to help fund the development of alternative services in the community until savings accrue from hospitals identified for closure.

Some $£ 100$ million of NHS funds has been allocated this year through the joint financing arrangements for the development of community care by local authorities and voluntary organizations. This brings the total sum allocated since the arrangements were set up to well over $£ 500$ million.

You ask about Government policy 'for filling the gaps, when closures are approved' and people do not come forward for joint working. The short answer here is that we do not mean this position to arise. Ministers have to approve every closure, or even changed use, of a hospital. We would not give approval to the closure of a mental illness hospital unless detailed plans were in existence to replace its services by those better services we have been chasing for so long.

I should finally reply to three smaller points in your letter. First, after discussion with North West Thames RHA we have been unable to confirm an increase in mental illness waiting lists; perhaps you would check your information.

Second, I agree that there is going to be a need for more than 2,000 community psychiatric nurses: I did not quote this figure as a target. You will be glad to know that a number of regions are now including target ratios in their Strategic Plans. One region, for example, is now quoting a target figure of $1 \mathrm{CPN}$ to 10,000 population-nationally this would imply about 4,700 nurses. (This is just the sort of point which I hope the consultation process will clarify at district level.)

Finally, you mention St Wulstan's. I agree that St Wulstan's is unique and was undoubtedly a pioneer in psychiatric rehabilitation 20 years ago. But times and methods of treatment change. Naturally the needs of patients as individuals must always come first. We are concerned about the future of patients currently being treated in St Wulstan's and have asked that the Regional Health Authority make arrangements for existing patients to be individually and sympathetically assessed by a multidisciplinary team to decide their future form of care. The money saved on the running of St Wulstan's will be spent on further developing patient services in the West Midlands region.

In summary I can say that I share your objectives with regard to severely mentally ill people. We differ perhaps in our approach to the subject. It is healthy to hammer out our differences in discussion, and I am pleased to have had your views, as also the enclosures to your letter.

Yours sincerely

Kenneth Clarke

\section{AUTP Postgraduate Training in Behavioural Psychotherapy}

The Association of University Teachers of Psychiatry with the Institute of Psychiatry runs an annual course in behavioural psychotherapy mainly intended for consultants and senior registrars and those of equivalent status, including specialist psychotherapists. The forthcoming course will be mainly for Psychiatric Tutors of the Royal College of Psychiatrists, but a limited number of other places may be available.

The course will begin with a two-day workshop on 25 and 26 September 1985. This will include the following components: theoretical background, demonstration of treatments and participant practice in small groups. After the workshop participants will be asked to undertake behavioural treatment of their own patients in their own centres, and later also to supervise other trainees. Participants will be supervised in small groups at monthly intervals in half-day sessions over the following academic year.

The course is organized on lines which qualify for local funding assistance under Study Leave Regulations of the BPMF. Cost of the combined workshop and monthly supervision over the following academic year is $£ 245$.

Applicants should write, including a brief curriculum vitae, to Professor Isaac Marks at the Institute of Psychiatry, De Crespigny Park, Denmark Hill, London SE5 8AF, where the course will be held. 